\title{
Difficult Cases and the Epistemic Justification of Moral Belief*
}

\author{
Joshua Schechter
}

Some moral questions are easy. Here are a few familiar examples: Should I set this cat on fire? ${ }^{1}$ Should I save that child from drowning? ${ }^{2}$ Should I tell the murderer at the door where to find his next potential victim? $?^{3}$ Indeed, such questions are so easy that there seems something problematic in even asking the questions.

On the other hand, some moral questions are difficult. ${ }^{4}$ Some examples of difficult moral questions concern unusual situations that (nearly) only ever occur in philosophical thought experiments, such as those involving ticking time bombs or runaway trolleys. Other examples concern real world life-or-death situations, such as wars against aggression (with their attendant questions about proper conduct in war). But there are many difficult moral questions that are much more commonplace. Here are a few: Should one send one's child to public or private school, given that one lives in such-and-such a community? Is it morally permissible to eat certain kinds of meat? When and how should one respond to minor occurrences of rude or unpleasant behavior by others? And so on. ${ }^{5}$

I expect that some of these examples will be contentious. Perhaps you think, for instance, that it is obvious that one should always send one's child to the best available school. Or perhaps you think that it is obvious that meat eating is always morally wrong. But I suspect that no one will disagree with the general point: There are difficult moral questions and such questions are rife in everyday life.

In some cases, the difficulty of a moral question is in part due to our ignorance about non-moral matters: Just how big an educational difference is there between the local public and private school? Just how unpleasant are the lives of "humanely raised" chickens? But in many cases, even if we had all of the relevant non-moral information, the moral questions would remain difficult. Difficult moral questions typically involve multiple morally relevant considerations that push in different directions. It is not always transparent what the contents of the morally relevant considerations are, how strong the considerations are, or how the considerations ought to be weighed against one another. ${ }^{6}$ This is part of what makes the moral questions difficult.

\footnotetext{
* This is the penultimate draft of a paper forthcoming in Russ Shafer-Landau (ed.) Oxford Studies in Metaethics, volume 12 .

${ }^{1}$ Harman (1977).

2 Singer (1972).

${ }^{3}$ Kant (1797).

${ }^{4}$ Witness the title of Harman (ms).

${ }^{5}$ That a moral question is difficult does not entail that it has no answer or that it involves a moral dilemma (in the sense that all available courses of action are impermissible). I do not have an illuminating positive characterization of what it is for a moral question to be difficult, but the notion is meant to be akin to the notion of a difficult practical question or a difficult problem in mathematics.

${ }^{6}$ Moral considerations can also interact in ways that don't involve simple weighing - e.g., one consideration may undermine another. For simplicity, I'll ignore this complication in what follows.
} 
This paper concerns the epistemology of difficult moral cases where the difficulty is not traceable to ignorance about non-moral matters. In what follows, I will do two things. First, I will argue for a principle concerning the epistemic status of moral beliefs about difficult moral cases. The basic idea behind the principle is that one's belief about the moral status of a potential action in a difficult moral case is not epistemically justified unless one has some appreciation of what the relevant moral considerations are and how the considerations bear on the moral status of the potential action. (As we'll see, a correct statement of this principle will require several refinements.) Second, I will argue that this epistemic principle has important ramifications for moral epistemology and moral metaphysics. It puts pressure on some views of the epistemic justification of moral belief, such as ethical intuitionism and reliabilism. It puts pressure on some antirealist views of moral metaphysics, including simple versions of relativism. It also provides some direct positive support for broadly realist views of morality. ${ }^{7}$

This paper will proceed as follows. In the next section, I will argue for and develop the epistemic principle concerning difficult moral cases. In section 2 , I will consider several objections to the principle. Finally, in section 3, I will show how the epistemic principle has important ramifications for moral epistemology and moral metaphysics.

\section{Difficult Moral Cases}

Consider some difficult moral decision between two potential courses of action, where there are relevant moral considerations pushing in both directions. Suppose the difficulty of the case does not stem from any ignorance of non-moral matters. Indeed, suppose that everyone is well informed about all of the relevant non-moral facts (though perhaps not under that description). ${ }^{8}$

There are interesting questions about the moral status of actions in such cases. For instance, just what is required of an agent in order to make an action in a difficult moral case count as morally worthy? But that's not my topic here. Rather, I would like to focus on the epistemic status of moral beliefs concerning such cases. The question I'm interested in here is: When is a moral belief concerning a difficult moral case epistemically justified? ${ }^{9}$

By "moral belief", I mean a belief that attributes a moral status to one of the potential courses of action - for instance, a belief that the course of action is morally right, permissible, or obligatory, or that it is morally wrong, impermissible, or optional. I also mean to include comparative moral judgments - for instance, the belief that one of the potential courses of action is morally better (or worse) than the other. ${ }^{10}$

\footnotetext{
${ }^{7}$ I suspect that the issues raised in this paper concerning the epistemology of beliefs about difficult moral cases have close parallels for beliefs about difficult epistemic cases.

${ }^{8}$ The difficult moral case may be a current situation that requires immediate attention. It may be an actual or potential future situation. Or it may be a merely possible situation in some far off possible world. As far as I can tell, the differences between these kinds of cases won't matter in what follows.

${ }^{9} \mathrm{I}$ 'm assuming, of course, that moral beliefs can be epistemically justified or unjustified. One might reject this claim, but that would do great violence to our conception of moral thought and talk.

${ }^{10}$ These are examples of beliefs that involve thin moral concepts. An anonymous referee asks whether my discussion extends to beliefs that involve thick moral concepts (such as the concepts of courage and cruelty). The short answer is that I don't know - whether it does will depend on the correct semantic account of thick concepts.
} 
The first claim that I'd like to make about the epistemology of difficult moral cases is this: A thinker cannot be epistemically justified in directly inferring from a complete non-moral description of a difficult moral case to a moral belief about the case. That is, the thinker cannot be epistemically justified in moving from the premises to the conclusion in a single step, directly basing the belief in the conclusion on beliefs in the premises (and nothing else). Such an inference would be a case of bad (that is, unjustified) reasoning.

Why think this? I don't have any fancy philosophical argument from general (and contentious) epistemic or moral principles. Rather, when considering cases, the claim simply seems evident.

Consider the question of whether one should one send one's child to public or private school, given that one lives in such-and-such a community. (Substitute your favorite difficult moral case if you don't like that one.) Suppose a thinker knows all of the relevant non-moral information about the case - e.g., the educational differences between the schools, the social differences between the schools, the difference to public finances, and much more besides. Suppose the details of the case are such that the case is a difficult one and there are considerations that push in both directions. If a thinker were to directly move in thought from the body of non-moral information to a moral conclusion without somehow processing the information - without extracting the morally relevant considerations, recognizing them as morally relevant, weighing them against one another, and evaluating how they bear on the decision - the thinker's belief would intuitively be unjustified. And similarly for other difficult moral cases.

It is too strong to require that the thinker explicitly consider the morally relevant considerations and how they bear on the decision. That would be to make the justification of moral beliefs much too hard to acquire. But, to be epistemically justified, the thinker had better have some kind of appreciation of the relevant moral considerations and how they bear on the decision. This appreciation might consist in explicit beliefs or it might consist in tacit mental states. ${ }^{11}$ But such appreciation had better play some role in the inference for it to be a justified one. ${ }^{12}$

It is worth saying a bit more about what I mean by "appreciation" here. In what follows, I would like to stay neutral on whether appreciation can be identified with a more familiar attitude - for

\footnotetext{
${ }^{11}$ Could some instances of appreciation be purely sub-personal? (This would be akin to how grammatical rules play a role in our cognitive modules for generating and interpreting language.) I suspect sub-personal states cannot play the requisite epistemic role, and that we should restrict appreciation to person-level cognitive states that aren't encapsulated in some cognitive module. But I should confess that I'm not confident here.

${ }^{12}$ This isn't merely the is/ought gap. There are two main reasons for this. First, the is/ought gap is best understood as a claim about entailment, not inference. In some easy moral cases, one can directly infer from a non-moral description of the case to a moral belief. For instance, perhaps one can directly infer from the description of a case in which a potential action will obviously cause a great deal of suffering (and the alternatives will not) to the conclusion that the action is pro tanto morally wrong. The moral truth that causing suffering is pro tanto wrong will presumably play a role in the explanation of why the action is pro tanto wrong. And the non-moral description of the case will not - in the absence of the moral truth - entail that the action is pro tanto wrong. But the thinker need not appreciate the moral truth for the inference to be a justified one. Second, even were we to add the relevant general moral truths to the non-moral description of a difficult moral case, a thinker could not directly infer from the (enhanced) description to a moral belief about the case. For the inference to be a justified one, the thinker would still need to process the information - extract the morally relevant considerations, recognize them as morally relevant, weigh them against one another, and so on.
} 
instance, justified belief. But what is important for my purposes is that appreciation is a representational, categorical (that is, non-dispositional), enduring cognitive state with a positive epistemic status. Otherwise, it is difficult to see how appreciation could play an important justificatory role in our thought.

It is also worth saying a bit more about just how much appreciation is necessary for a thinker to be epistemically justified. There is significant complexity here. To be justified, a thinker need not appreciate all of the morally relevant considerations and exactly how they bear on the decision - such a requirement would clearly be much too strong. On the other hand, a moral belief about some difficult moral case cannot be justified if the thinker only appreciates a few marginal considerations and has no appreciation of the central issues in play. Some intermediate constraint is required. Similarly, to be justified, a thinker need not appreciate the exact content of the morally relevant considerations - the content of the thinker's appreciation may be unspecific or may not quite match what is truly morally relevant (or what the thinker is justified in taking to be morally relevant). On the other hand, a moral belief about some difficult moral case cannot be justified if the content of the thinker's appreciation is highly non-specific or is very far away from what is truly morally relevant (or from what the thinker is justified in taking to be morally relevant).

The natural suggestion to make here - albeit a highly programmatic one - is that whether the thinker needs to appreciate a morally relevant consideration will in part depend on whether the consideration turns out to be significant to the moral status of the relevant course of action given the other considerations in play. If, for example, it is overdetermined that one course of action is morally better than another, the thinker may not need to appreciate even a very strong morally relevant consideration. Similarly, how specific the thinker's appreciation has to be will in part depend on how significant such specificity is to the moral force of the consideration. And something similar will be true for how closely the thinker's appreciation must match what is truly morally relevant (or what the thinker is justified in taking to be morally relevant).

My first claim is a claim about the epistemic status of inferences. There is a natural companion claim about the epistemic status of beliefs. This second claim is the main focus of the remainder of this paper.

We can roughly state the second claim as follows: A thinker cannot have an epistemically justified moral belief concerning a difficult moral case unless the thinker has some appreciation of the relevant moral considerations and how they bear on the choice between courses of action. In particular, the belief cannot be directly based on the body of non-moral information specifying the details of the case.

Why think this? Again, I don't have any fancy philosophical argument. But reflection on difficult moral cases suggests that this epistemic principle, or a principle in the ballpark, is correct.

My second claim is not quite right as stated. There are two complications that need to be addressed. The first is that a thinker can have a justified moral belief about a difficult moral case 
that is held on the basis of testimony. ${ }^{13}$ A thinker can also have a justified moral belief about a difficult moral case that is held on the basis of a track record argument - for instance, one might have inductive grounds to trust one's immediate "gut" reaction across some range of cases. Appreciation of the relevant moral considerations (or how they bear on the case) is not necessary for a belief held on the basis of testimony or a track record argument to be justified.

We can handle this complication by restricting the epistemic principle. Testimony and track record arguments are what we might call "non-canonical" bases for moral belief. The flow of justification in such cases is indirect and circuitous. ${ }^{14}$ By contrast, the canonical way to hold a moral belief is on the basis of an argument that appeals to a body of information about the relevant case. ${ }^{15}$ A natural restriction to make is to moral beliefs concerning difficult cases held in a canonical way.

There is a second complication. A thinker can have a justified moral belief that is held on the basis of some justified misimpression about what the relevant moral considerations are or how they bear on the case. So it is not a requirement on having an epistemically justified moral belief (concerning a difficult case and held in a canonical way) that one correctly appreciate the relevant moral considerations and how they bear on the case. The formulation of the second claim must take this into account, too. ${ }^{16}$

What these two complications suggest is that the right formulation of the principle is something like this:

A moral belief concerning some difficult moral case that is held in a canonical way is not epistemically justified unless the thinker has some appreciation - either explicitly or tacitly - of what the relevant moral considerations are and how they bear on the case (or has a justified misimpression about what the relevant moral considerations are and how they bear on the case).

This principle is a mouthful. And the issues here are delicate - the principle presumably needs some extra fussing. But the core idea is simple: Caveats aside, one's belief about the moral status of a potential action in a difficult moral case is not epistemically justified unless one has some

\footnotetext{
${ }^{13}$ Several philosophers have suggested that there is something odd with reliance on moral testimony. Some have gone so far as to claim that (pure) moral testimony cannot yield knowledge (or, presumably, justified belief). For relevant discussion, see Hopkins (2007), McGrath (2011), and Nickel (2001). There are strong reasons to think that testimony can provide moral knowledge (and justified moral beliefs). See Jones (1999) and Sliwa (2012). But even if it cannot, this would not pose any problem to my main claim.

${ }^{14}$ It is difficult to precisely characterize the distinction between canonical and non-canonical bases for belief. A natural first thought is that the justification of beliefs held on the basis of testimony or track record arguments is in some sense "parasitic". But more needs to be said here.

${ }^{15}$ The canonical basis for some class of beliefs may not be the most common basis of that class of beliefs. Consider the case of mathematics. The canonical basis for a mathematical belief is a proof. But a large proportion of mathematical beliefs are held on the basis of testimony rather than proof.

${ }^{16}$ This complication could be avoided if the principle were formulated in terms of knowledge rather than justification. However, there are reasons to formulate the principle in terms of justification. The principle concerning justification is more general and more fundamental. Moreover, I suspect that knowledge is a fairly uninteresting epistemic status. See Schechter (forthcoming a).
} 
appreciation of what the relevant moral considerations are and how the considerations bear on the moral status of the potential action. This is an intuitive thought.

A few clarifications may be helpful here. The epistemic principle provides a necessary condition on epistemic justification. More specifically, it provides a necessary condition on doxastic rather than propositional justification. A thinker is propositionally justified in believing some proposition if (more-or-less) the thinker has good epistemic grounds for believing it. A thinker's belief is doxastically justified if (more-or-less) the belief itself is based on good epistemic grounds. These can come apart - a thinker may have good grounds for believing some proposition, and may in fact believe it, but may believe it on bad grounds (e.g., on the basis of wishful thinking). Such a thinker has propositional justification to believe the relevant proposition. But such a thinker's belief is not doxastically justified. The epistemic principle stated above concerns whether a moral belief is held on good grounds, and thus concerns doxastic justification.

As stated, the epistemic principle is restricted to moral beliefs concerning difficult moral cases. However, the phenomenon does not, at base, concern difficult moral cases. In many easy moral cases, to have an epistemically justified belief (held in a canonical way) also requires that one have some appreciation of the relevant moral considerations. There are two reasons that the principle is restricted to difficult cases. First, difficult cases provide the most intuitively compelling illustrations of the phenomenon. Second, it is difficult to see how to draw the dividing line between the moral beliefs that do and the moral beliefs that don't require appreciation of the relevant moral considerations in order to be justified. Restricting the principle to difficult moral cases avoids the need to determine exactly how to draw this dividing line.

Before I turn to objections to the epistemic principle, there is one final point that I should make. The phenomenon here is not particular to the moral domain. There are analogous facts concerning other areas of thought. For instance, one cannot be justified in directly inferring a complex scientific theory from a large body of evidence, without having some appreciation of which parts of the evidence are relevant and how the evidence supports the theory. Similarly, one cannot be justified in directly inferring a difficult mathematical theorem from the relevant axioms, without having some appreciation of a proof of the theorem (or some other kind of argument for its truth). In each of these cases, one cannot simply "leap" from the evidence or the axioms to the conclusion. ${ }^{17}$

These are claims about inference. There are also analogous claims about belief. One cannot have a justified belief in a complex scientific theory (held in a canonical way) unless one has some appreciation of how the evidence supports the theory. One cannot have a justified belief in a difficult mathematical theorem (held in a canonical way) unless one has some appreciation of a proof of the theorem (or some other kind of argument for its truth). In each of these cases, one cannot simply have a belief that is directly supported by a mass of scientific evidence or a collection of simple axioms. To be justified, the belief needs to be based on some intermediate structure. ${ }^{18}$

\footnotetext{
${ }^{17}$ Schechter (forthcoming b).

${ }^{18}$ These analogies are not perfect. One important difference is that the moral side of the analogy concerns a judgment about a case. By contrast, the scientific side of the analogy concerns belief in an entire scientific theory. A
} 
Interestingly, this phenomenon does not seem to extend to all areas of thought. Plausibly, an analogous claim does not hold for beliefs that attribute predicates of personal taste, such as beliefs about what's funny or what's delicious. Consider what might be thought of as difficult questions involving predicates of personal taste: Are durians delicious? Is some particular mildly awkward joke genuinely funny? Having a justified belief about whether durians are delicious doesn't require that the thinker have any appreciation of relevant considerations. One can simply find durians to be delicious (or disgusting) and that suffices. ${ }^{19}$ Similarly, having a justified belief about whether a mildly awkward joke is funny doesn't require that the thinker have any appreciation of relevant considerations. One can simply find the joke funny (or unfunny) and that suffices. Of course, there are cases where a thinker's attribution of a predicate of personal taste may be based on the appreciation of relevant considerations - such as an art historian's belief about whether a painting is beautiful or a whisky connoisseur's belief about whether some libation is delicious. But the point is that this kind of appreciation is not required for a belief attributing a predicate of personal taste to be justified. So there is a striking difference between the epistemology of morality, science, and mathematics on the one hand, and humor, deliciousness, and other predicates of personal taste on the other.

\section{OBJECTIONS AND REPLIES}

Let me now turn to objections one might have with the epistemic principle stated above. I will look at five concerns: One to the effect that the principle is familiar and uninteresting, one that suggests that we should modify the principle to make use of the notion of moral understanding, one that suggests that the principle is over-intellectualized, one that suggests that the intuitive motivations for the principle are not connected to epistemic justification but to a different epistemic or moral status, and finally, one that suggests that the principle is false because of the phenomenon of "moral insight".

Objection 1: The epistemic principle can be restated in terms of reasons. When so restated, the principle is familiar and uninteresting.

Reply: It may be right that the epistemic principle can be restated in terms of reasons. ("Considerations" does seem to be synonymous with "reasons".) ${ }^{20}$ But this doesn't make the epistemic principle familiar and uninteresting.

There are two ways I can see of trying to develop this line of objection. The first is to claim that the epistemic principle trivially follows from the general claim that a belief is doxastically justified only if it is appropriately based on reasons.

perhaps closer analogy would be between a moral judgment about a case and a scientific claim about the result of an experiment (or, alternatively, between belief in a moral theory and belief in a scientific theory). A second important difference will emerge in the response to Objection 1 below.

${ }^{19}$ Presumably, the thinker will form a belief about whether durians are delicious on the basis of the flavor (and texture and ...) of durians. The point is that, in order for the belief to be justified, the thinker need not extract relevant features of the taste of durians, recognize them as relevant, and weigh them against one another. The thinker need only find durians delicious. Thanks to an anonymous referee for pressing me on this issue.

${ }^{20}$ I didn't originally state the principle in terms of reasons because I think reason-talk is the source of much confusion in philosophy. 
It is plausible that, very generally, beliefs are epistemically justified only if they are appropriately based on reasons. However, the reasons at issue in that general claim are (epistemic) reasons that support believing the relevant proposition. By contrast, the reasons at issue in the epistemic principle stated above are reasons that contribute to determining the truth value of the relevant proposition. ${ }^{21}$ One way to see the contrast involves cases of testimony. One can have a justified belief that is held on the basis of the testimony of a reliable source. In such a case, one's reason to believe the proposition that $\mathrm{p}$ is that so-and-so said that $\mathrm{p}$ and so-and-so is reliable about whether $\mathrm{p}$. This is a reason that supports believing the proposition that $\mathrm{p}$. But (marginal cases aside), it does not make the proposition true or otherwise contribute to determining the truth value of the proposition. So the epistemic principle is not a trivial consequence of the claim that beliefs are justified only if they are appropriately based on reasons.

Even so, one might worry that the restatement of the epistemic principle in terms of reasons is anodyne. The restated principle is presumably something like: A thinker's moral belief about a difficult moral case held in a canonical way is not justified unless the thinker has some grasp of the reasons that help to determine the truth value of the proposition believed. And one might think that this follows from the general claim that a thinker's belief held in a canonical way is not justified unless the thinker has some grasp of the reasons that contribute to determining the truth value of the relevant proposition. So the second way I can see of trying to develop this line of objection is to claim that the epistemic principle trivially follows from a general claim concerning beliefs held in canonical ways.

There are two problems with this suggestion. First, even if the general claim were true, it would not be anodyne. It would be a highly substantive claim about epistemic justification. Second, the general claim is not true. It does not hold for belief in complex scientific theories or difficult mathematical theorems. To have a justified belief in some complex scientific theory (held in a canonical way), one does not need to appreciate the considerations that help to explain the truth of the scientific theory, whatever those might be. A body of scientific data does not typically explain the truth of the theory it supports - rather, the theory explains the data. ${ }^{22}$ Similarly, to have a justified belief in some difficult mathematical theorem (held in a canonical way), one does not need to appreciate the considerations that help to explain the truth of the theorem. Some mathematical proofs are explanatory and others are not. A justified belief in some mathematical theorem may be based on the appreciation of a non-explanatory proof.

There are further counterexamples to the general claim. It does not hold for beliefs in basic logical, mathematical, or conceptual truths - including the beliefs that if it is raining outside then it is raining outside, that 0 is a number, that red is a color, and so forth. It does not hold for moral beliefs about some easy moral cases. And it does not hold for beliefs that attribute predicates of personal taste, such as judgments about what is funny or what is delicious.

Objection 2: The epistemic principle should be modified to make use of the notion of moral understanding. According to the modified principle, a moral belief about a difficult case is only justified if the thinker has some moral understanding of the relevant issues.

\footnotetext{
21 "Determining" is not being used here in an epistemic sense. Determination is an asymmetric metaphysical explanatory relation akin to grounding.

${ }_{22}$ Presumably, the same is true for belief in general moral theories.
} 
Reply: If "moral understanding" is simply a matter of having appreciation of the relevant moral considerations and how they bear on the moral status of potential courses of action, then I have no quarrel with this suggestion. ${ }^{23}$ But if "moral understanding" is used in a different way, then depending on the details of the account, the resulting principle will likely be false.

The most developed account of moral understanding of which I am aware is due to Alison Hills. ${ }^{24}$ On Hills's view, understanding why $p$ is a matter of having certain abilities. In particular:

If you understand why $p$ (and $q$ is why $p$ ) then in the right sort of circumstances, you can successfully:

(i) follow an explanation of why $\mathrm{p}$ given by someone else;

(ii) explain why $p$ in your own words;

(iii) draw the conclusion that $\mathrm{p}$ (or that probably $\mathrm{p}$ ) from the information that $\mathrm{q}$;

(iv) draw the conclusion that $\mathrm{p}^{\prime}$ (or that probably $\mathrm{p}^{\prime}$ ) from the information that $\mathrm{q}^{\prime}$ (where $\mathrm{p}^{\prime}$ and $\mathrm{q}^{\prime}$ are similar but not identical to $\mathrm{p}$ and $\mathrm{q}$ );

(v) given the information that $\mathrm{p}$, give the right explanation, $\mathrm{q}$;

(vi) given the information that $\mathrm{p}^{\prime}$, give the right explanation, $\mathrm{q}^{\prime}$.

Hills (2009: 102-103)

Hills also argues for a connection between moral understanding and moral epistemology. She claims that just as knowledge is the epistemic ideal for ordinary non-moral belief, ${ }^{25}$ moral understanding is the epistemic ideal for moral belief (or, perhaps, the primary component of the epistemic ideal for moral belief). In very rough outline, Hills's argument is as follows: We can determine the epistemic ideal for a class of beliefs by looking at the function that those beliefs serve in action. Moral beliefs have the primary function of enabling us to engage in morally worthy action. An agent's action based on her moral beliefs is morally worthy only if the agent understands why the action is right. So the epistemic ideal for moral belief is moral understanding. ${ }^{26}$

Hills does not make any claims about what is required for a moral belief to be epistemically justified. But one might try to extend her line of thought and claim that to be epistemically justified in holding a moral belief requires one to have moral understanding (or, perhaps, quasiunderstanding, where quasi-understanding is just like understanding but isn't factive). The idea would be that we can determine the nature of epistemic justification for a class of beliefs by looking at the function that the beliefs serve in action. A belief is epistemically justified if the belief has an epistemic status that is sufficient for serving that function, or would be sufficient for serving that function were the world to cooperate, or something similar. Thus, given Hills's

\footnotetext{
${ }^{23}$ Some philosophers characterize understanding in terms of knowledge. For instance, one might try to analyze understanding why $\mathrm{p}$ as knowing the causes or grounds of $\mathrm{p}$. For proposals in this ballpark, see Grimm (2006), Khalifa (2011), Kelp (2015), and Sliwa (2014). This kind of proposal doesn't yield a notion of moral understanding suitable for playing the central role in the epistemic principle stated above. While having knowledge of relevant considerations (and how they bear on the case) may be sufficient for the kind of appreciation at issue in the principle, it is not necessary - justified belief would presumably suffice.

${ }^{24}$ Hills (2009; 2010; forthcoming).

${ }^{25}$ I deny this claim in my (forthcoming a).

${ }^{26}$ Hills (2010, chapter 10).
} 
view of the function of moral belief, for a moral belief to be justified requires that it be appropriate connected to moral understanding (or to quasi-understanding).

There is much of interest in Hills's discussion of moral understanding, and in its connection to moral epistemology. However, moral understanding, as Hills characterizes it, cannot be a requirement on epistemically justified moral belief (even restricted to beliefs about difficult moral cases held in a canonical way). One issue is that Hills's account of moral understanding requires a number of linguistic abilities that are simply irrelevant to epistemic justification - for instance, the ability to understand someone else's explanation and the ability to articulate an explanation oneself. One can have a justified belief that some action is wrong while being hopeless at interpreting others or in formulating a coherent linguistic explanation of why the action is wrong. ${ }^{27}$

Hills does provide an account of what she calls "implicit understanding" that doesn't involve such heavy-duty linguistic abilities. Her account of implicit understanding retains clauses (iii) and (iv) from her definition of explicit understanding but jettisons the rest:

[Y]ou tacitly or implicitly understand why $\mathrm{p}$, if $\mathrm{p}$ is true and $\mathrm{q}$ is why $\mathrm{p}$, provided that you believe that $\mathrm{p}$ and under normal circumstances you can draw the conclusion that $\mathrm{p}$ (or that probably $\mathrm{p}$ ) from the information that $\mathrm{q}$; and you can draw the conclusion that $\mathrm{p}^{\prime}$ (or that probably $\mathrm{p}^{\prime}$ ) from the information that $\mathrm{q}^{\prime}$ (where $\mathrm{p}^{\prime}$ and $\mathrm{q}^{\prime}$ are similar to but not identical to $p$ and $q)$. Hills (2015, italics in original)

Hills doesn't seem to think that implicit moral understanding plays an important role in our moral lives. But perhaps one could make use of it in the present context and modify the epistemic principle I argued for above to make use of the notion of implicit moral understanding.

This suggestion will not work, either. As Hills characterizes it, implicit understanding is a matter of having the ability to get things right about some range of cases. But that is not necessary for having an epistemically justified moral belief (even concerning a difficult moral case and held in a canonical way). One can imagine a thinker who has a justified belief about the moral status of an action in some particular difficult moral case because she sees exactly why the relevant action has the moral status it does. This is compatible with the thinker not being able to extend this insight to neighboring cases, perhaps because of some blind spot or mental incapacity. Such a thinker is epistemically (and perhaps morally) deficient. Such a thinker lacks something valuable. But such a thinker's belief does not seem epistemically unjustified. Compare the case of mathematics: A thinker can be able to do a particular math problem and come to a justified belief about the correct answer even if he or she is incapable of doing closely related problems. Such a thinker has an epistemic (and mathematical) deficiency. But the thinker's mathematical belief is not unjustified.

\footnotetext{
${ }^{27}$ In response to this worry, Hills might suggest that in her characterization, "the right sort of circumstances" should be interpreted to require that the agent possesses the general linguistic abilities needed for the comprehension and production of explanations. This response seems ad hoc. More importantly, it suggests that Hills's account does not get at what is fundamental to moral understanding.
} 
This is a problem with the necessity of (Hillsian) moral understanding for epistemic justification. There is also a concern with its sufficiency: Suppose that the relevant range of moral cases surrounding some difficult moral case fits a very simple pattern. That is, suppose that while some (or all) of the cases in the range of cases is difficult, when all of the relevant moral considerations are taken into account, the pattern concerning the moral status of potential actions is very simple. (Perhaps one of the potential actions is always the only permissible action. Or perhaps there is some kind of sharp cutoff.) We can imagine that this pattern is hardwired into a thinker's brain enabling the thinker to get the right answer across the entire range of cases. Intuitively, this is insufficient for the thinker to satisfy whatever the relevant epistemic constraint is here. What seems required, instead, is that the thinker has some appreciation of what the relevant moral considerations are and how they bear on the moral status of a course of action. That a thinker gets it right across a range of cases is typically an indication - a symptom - that the thinker has some appreciation of the relevant considerations. But the two can come apart. When they do, what is epistemically important is appreciating the relevant moral considerations, not getting it right across a range of cases.

Perhaps the difficulties here are due to the account of moral understanding. Could a different account of moral understanding do a better job? Perhaps. But I suspect that any plausible proposal would end up being a notational variant of the principle I defended above.

There is a deeper problem with the appeal to moral understanding in this context. Put aside the details of Hills's account of moral understanding and focus on the thought that moral understanding is whatever epistemic status is required for morally worthy action. There are strong reasons to think that if moral understanding is tied to morally worthy action in that way, it should not also be playing a role in the epistemic justification of moral belief. Morally worthy action and epistemically justified moral belief are just too different. Morally worthy action plausibly requires an agent to act out of some suitable moral concern. ${ }^{28}$ That's not true for the justification of moral belief - an agent can perfectly well have an epistemically justified moral belief and care little (or not at all) about the relevant moral issues. ${ }^{29}$ More importantly, it is important not to over-intellectualize morally worthy action. ${ }^{30}$ One's action can be morally worthy even if one has unjustified beliefs about what morality requires, is a very poor reasoner about moral matters, and so on. (This can be illustrated by the now familiar Huck Finn case.) ${ }^{31}$ The same is not true for the epistemic justification of moral belief. Epistemic justification of moral belief is a much more intellectualized notion. What this suggests is that we should be wary of the thought that there is a common epistemic requirement on morally worthy action and epistemically justified moral belief.

Objection 3: The epistemic principle is false since it is over-intellectualized. It requires too much of thinkers to count as epistemically justified.

\footnotetext{
${ }^{28}$ See, for instance, Arpaly (2002).

${ }^{29}$ This claim is incompatible with very strong versions of motivational internalism. But such strong versions are implausible.

${ }^{30}$ Arpaly (2002).

${ }^{31}$ Bennett (1974).
} 
Reply: The epistemic principle defended above does place a non-trivial intellectual requirement on the epistemic justification of moral beliefs (about difficult moral cases and held in a canonical way). But that is as it should be. The question of whether a belief is epistemically justified doesn't even arise unless the thinker is sufficiently cognitively sophisticated. Whether a belief is epistemically justified is an intellectual matter.

Of course, it is important that the proposed principle not put too strong an intellectual requirement on thinkers. But I don't see that it does. Recall that the epistemic principle does not require that thinkers have explicit beliefs about what the morally relevant considerations are and how they bear on the case - appreciation may be constituted by some merely tacit mental state. The epistemic principle does not require that thinkers appreciate all of the morally relevant considerations, have maximally specific representations of the relevant considerations, and get their contents exactly right. Something much weaker suffices.

The typical way to press an over-intellectualism worry is in terms of a "young children and sophisticated non-human animals" objection. According to the principle defended above, children are able to have epistemically justified beliefs about difficult moral cases held in canonical ways if they are able to have some appreciation of the relevant moral considerations and how they bear on the case. Importantly, this doesn't require that the children are able to articulate the considerations, communicate an explanation to others, or anything like that. It just requires that the children have some grasp of what's going on in the cases. Plausibly, even fairly young children can have such a grasp, at least about cases that are not too difficult. So there is no bar to them having epistemically justified moral beliefs about such cases. This strikes me as the correct verdict.

Now consider the case of a very young child, one who counts as a genuine reasoner but who is unable to appreciate relevant moral considerations or how they bear on moral questions. The epistemic principle defended above does not rule out the possibility that such a thinker can have a justified moral belief about a difficult moral case. Such a thinker may have an epistemically justified belief on the basis of testimony. The principle does entail that such a thinker is unable to have an epistemically justified belief about a difficult moral case held in a canonical way. But again that strikes me as the correct verdict.

It may be helpful to compare the case of mathematics. A child may have an epistemically justified belief in some non-trivial mathematical proposition by reasoning through (something like) a proof. This can be true even if the child is incapable of clearly communicating the proof to others. By contrast, a very young child will be unable to have an epistemically justified belief in a mathematical proposition via anything like a proof. Such a child may nonetheless have an epistemically justified belief based on testimony. The moral case is analogous.

Objection 4: The intuitions supporting the epistemic principle do not genuinely support a principle concerning epistemic justification. Rather, they support a principle concerning some other moral or epistemic status (e.g., morally worthy action, morally virtuous character, understanding, or epistemically virtuous character). 
Reply: A common objection to claims about justification (or knowledge, or another epistemic status) that are based on judgments about cases is that the intuitive basis for our judgments really concerns some other epistemic status - e.g., being a reasonable thinker - and we are misdescribing the cases. ${ }^{32}$ One might therefore worry that the intuitions supporting our epistemic judgments about difficult moral cases don't really concern epistemic justification but rather some other epistemic status (e.g., understanding or being an epistemically virtuous thinker) or perhaps some moral status (e.g., being in a position to engage in morally worthy action or having a morally virtuous character). The worry, then, is that I have misdescribed the cases.

In the abstract, this worry is not very concerning. For the worry to be pressing, one would need to provide a proposal about what the alternative status is, and some positive reason to think that this status - and not epistemic justification - is what's at issue. I would be very interested to hear any such proposal.

But there is more that can be said in defense of the claim that our judgments about difficult moral case are tracking an epistemic status rather than a moral one, and epistemic justification rather than some other epistemic status.

One complication that should be mentioned here is that "epistemic justification" is used in several different ways in contemporary epistemology. Contemporary epistemologists use the term to express different concepts - e.g., that which when added to true belief yields knowledge (Gettier cases aside), being appropriately based on the evidence, being permissibly held, being responsibly held, and so forth. Perhaps all of these concepts stand for the very same property. Perhaps not. But this polysemy has the potential to lead to confusion.

The concept of epistemic justification that is most relevant in the present context is that of epistemic responsibility. Some inferences are responsibly drawn and others are not. Some beliefs are responsibly held and others are not. The intuitions underlying the epistemic principle stated above are tied to this notion of epistemic responsibility. It is not epistemically responsible to directly infer from some description of the non-moral facts to a moral belief about some difficult moral case without having some appreciation of the relevant moral considerations and how they bear on the case. This is because such an inference involves "too large" a jump. If a jump is too large, it does not count as epistemically responsible.

As I argued above, there are related phenomena for complex scientific theories and for difficult mathematical theorems. One cannot be justified in inferring some complex scientific theory from some total body of evidence in a single step, without having any appreciation of what parts of the evidence are relevant and how the evidence supports the theory. Derivatively, one cannot have an epistemically justified belief in a complex scientific theory that is held in a canonical way unless one has some appreciation of what parts of the evidence are relevant and how the evidence supports the theory. And similarly for complex mathematical theorems.

In these cases, too, the relevant normative status is an epistemic one. (It is certainly not a moral status.) Again, it is epistemic responsibility. Inferring from a body of scientific evidence to a scientific theory in a single step is "too large" a jump. It is not an epistemically responsible

\footnotetext{
${ }^{32}$ For a nice instance of this strategy, see Lasonen-Aarnio (2011).
} 
inference to draw. Similarly, inferring from simple mathematical axioms to a complex mathematical theorem in a single step is too large a jump. It, too, is not an epistemically responsible inference to draw.

It would be uncomfortable to claim that what's going on in difficult moral cases is different from what's going on in cases of complex scientific theories or difficult mathematical theorems. The phenomena are broadly analogous. In each of these cases, moving from the input beliefs to the output belief in a single step, without any appreciation of how the inputs support the output, strikes us as too large a jump. So there is theoretical pressure to say that the same normative status is at issue. The most natural view is that in all of these cases, the normative status at issue is epistemic justification understood as responsibly held belief.

Objection 5: The epistemic principle is false because it is incompatible with the phenomenon of moral insight. A thinker can have an epistemically justified belief that comes in a "flash of insight" and is not based on the appreciation of relevant moral considerations. ${ }^{33}$

Reply: There does seem to be a phenomenon of moral insight. When considering a moral question, one can suddenly come to believe that some potential action is morally better than another in a flash of insight. It might be thought that this phenomenon is incompatible with the epistemic principle stated above.

There is a related worry about the case of mathematical inference. Consider the great Indian mathematician Ramanujan. Famously, Ramanujan stated many complex mathematical identities without having any conception of their proof. At least in several cases, they came to him via "mathematical insight". ${ }^{34}$ It might be thought that this puts pressure on my claim that one cannot have a justified belief in a complex mathematical theorem (held in a canonical way) unless one has some appreciation of how the axioms support the theorem.

These reactions to instances of moral and mathematical insight, however, are too quick. In some cases of insight, what may come "in a flash" is an appreciation of the relevant considerations or how they bear on the case. That is not incompatible with the epistemic principle stated above.

Perhaps we can imagine a case where all that comes in a flash is a "bare" moral or mathematical judgment. But even such a case isn't clearly a threat to the epistemic principle stated above. Suppose the relevant thinker has a track record of having such bare insights, checking up on them, and finding that they are correct. Such a thinker would have good inductive reason to believe the content of their bare insights. Such beliefs would be epistemically justified. But the source of the justification would include the inductive grounds - it wouldn't be the insight by itself.

Suppose instead that the relevant thinker has no track record of successful bare insights in the past - either there were no previous insights or the thinker did not check up on them and see whether their contents were true. It seems to me that such a thinker would not be epistemically

\footnotetext{
${ }^{33}$ Thanks to Michael Lynch for discussion of this issue.

${ }^{34}$ There is some reason to think that the standard story about Ramanujan is exaggerated. But that doesn't matter for my purposes. A fictionalized version will suffice.
} 
justified in believing the contents of the bare judgment. From the thinker's point of view, such a judgment would be a leap in the dark.

For there to be a compelling objection to the epistemic principle, one would have to describe a case in which a thinker had an insight that some potential action had a given moral status where (i) the insight did not come with any appreciation of the relevant moral considerations; (ii) the thinker did not have good inductive reasons to trust the content of her insights; and (iii) nonetheless, our reaction to the case is that the resulting moral belief is justified. I don't see any clear cases fitting that description.

\section{CONSEquences for Moral EPISTEMOlogy AND Moral Metaphysics}

There is positive reason to endorse the epistemic principle stated above (or a principle much like it). As far as I can tell, there are no devastating objections to the principle. In this section, I will turn to potential ramifications of the epistemic principle. I will argue that it has important consequences for moral epistemology and moral metaphysics.

\section{Moral Epistemology}

Let me begin with moral epistemology. The epistemic principle stated above puts pressure on many views of the epistemic justification of moral belief. For instance, it puts pressure on views of justification that appeal to intuition or rational insight.

On one kind of intuition-based view, a thinker is (pro tanto) propositionally justified in believing a moral claim if the claim intuitively seems to the thinker to be true. ${ }^{35}$ If the thinker goes on to form the belief on the basis of this intuition, the resulting belief is (pro tanto) doxastically justified. The idea here is that having an intuition is a matter of having a mental state with a certain kind of phenomenology - it is an "intellectual seeming" and has a "presentational phenomenology". Thinkers are (pro tanto) justified in believing the contents of their intuitions because of this phenomenology. Just as thinkers are justified in believing the contents of their perceptual seemings based on the phenomenology of perceptual experience, ${ }^{36}$ so too are thinkers justified in believing the contents of their intellectual seemings based on the phenomenology of intellectual experience. And this is where all of the justification for our moral beliefs ultimately stems from. Or so goes the story. ${ }^{37}$

\footnotetext{
${ }^{35}$ Huemer (2006).

${ }^{36}$ Pryor (2000).

37 "Intuition" and its cognates have been used in several different ways. According to a very different kind of intuition-based view, we have a cognitive faculty broadly analogous to perception that "puts us in touch" with the relevant facts. On this kind of view, the justification of beliefs based on intuition stems from a kind of cognitive contact or acquaintance with the relevant facts. See, for instance, BonJour (1997). This is a rather mysterious view that faces many familiar problems. (Most saliently, how are we supposed to have such cognitive contact? Noetic rays?) It also runs into difficulty with the epistemology of difficult cases. In particular, such a view owes us an explanation of why thinkers can't get in cognitive contact with the truth about the moral status of actions in difficult moral cases.
} 
The epistemic principle stated above puts pressure on this kind of view. The trouble is that it is possible for the answer to a difficult moral question to intuitively seem to be true, even if the thinker has no appreciation of the relevant moral considerations or how they bear on the case. It can simply appear to the thinker that such-and-such is the morally best course of action in the difficult moral case. But, if the epistemic principle is correct, such an intellectual seeming cannot justify a moral belief about a difficult case. ${ }^{38}$ Some appreciation of the relevant moral considerations or how they bear on the case is required. So either this kind of ethical intuitionist view is false or it needs to be supplemented with an explanation of why having an isolated intellectual seeming about the moral status of an action in a difficult moral case is impossible or does not provide justification. Giving such an explanation looks to be a difficult task.

Now consider a very different account of epistemic justification - reliabilism. ${ }^{39}$ On a simple version of reliabilism, a moral belief is (pro tanto) epistemically justified if the belief was formed using belief-forming methods that are suitably truth-conducive.

The epistemic principle stated above puts pressure on this kind of view, too. The trouble is that it is possible for a thinker to move from a non-moral description of a difficult moral case to a moral belief about the case using truth-conducive methods, even if the thinker has no appreciation of the relevant moral considerations or how they bear on the case.

In more detail: There are collections of difficult moral cases in which the right answer to the question of which course of action is morally best conforms to a simple pattern. Even though the cases are difficult, when all of the relevant moral considerations are taken into account, the pattern concerning the moral status of potential actions is straightforward. For instance, suppose the question of whether it is morally permissible to eat certain kinds of meat has a simple pattern of answers. (Perhaps the answer is always no, or perhaps there is a sharp cutoff so that, for instance, it is only permissible to eat animals without a certain physiological feature.) We can imagine a thinker who is hardwired in such a way that her moral judgments conform to the pattern. For instance, perhaps the thinker has a rule of inference that permits directly inferring from the premise that this is meat from an animal with a particular physiological feature to the conclusion that this is impermissible to eat. This rule of inference will be truth-conducive. So according to reliabilism, the resulting moral belief will be epistemically justified. But if the epistemic principle stated above is correct, in the absence of any appreciation of the relevant moral considerations and how they bear on the case, the thinker's belief will not be epistemically justified. So this form of reliabilism is false.

The problem for reliabilism extends to other accounts of justification and knowledge that appeal to truth-conduciveness, such as accounts in terms of the safety or sensitivity of one's beliefs. The epistemic principle stated above also poses problems for very different accounts of the epistemic justification of moral belief. For instance, it would seem to rule out simple evolution-based views according to which a thinker is (pro tanto) epistemically justified in employing any rule such that (i) employing the rule conferred a selective advantage on the thinker's ancestors and (ii) the rule

\footnotetext{
${ }^{38}$ I'd like to stay neutral here on whether an intellectual seeming can provide a small amount of justification for a moral belief about a difficult case. The point is that it cannot provide enough for the resulting belief to count as justified full stop.

${ }^{39}$ Goldman (1979).
} 
is part of a cognitive mechanism with an appropriately epistemic aim. It would seem to rule out views tied to psychological unavoidability according to which a thinker is (pro tanto)

epistemically justified in employing any rule that the thinker is psychologically unable to avoid employing. The difficulty is that none of these accounts - at least in their simplest and purest forms - are able to explain why appreciation of relevant moral considerations is needed for epistemically justified beliefs about morally difficult cases.

So the epistemic principle stated above provides a very strong constraint on acceptable accounts of the epistemic justification of moral belief. It rules out simple versions of many familiar views. Perhaps these views can be modified to conform to the constraint, but that increases the danger of ad hocery. It is not at all clear what view we should adopt that conforms to the constraint in a principled way. ${ }^{40}$

\section{Moral Metaphysics I}

Now let me turn to moral metaphysics. The epistemic principle stated above also puts pressure on many antirealist views of morality, including simple versions of moral truth relativism.

It is easiest to illustrate the problem with a toy version of an antirealist view. Consider a simple version of moral truth relativism according to which a moral claim is true relative to a thinker just in case the claim is entailed by (or otherwise comports with) the thinker's deepest moral commitments. This relativist view has epistemological consequences. Presumably on such a view, a thinker will be justified in having a moral belief if the belief is obviously entailed by the thinker's deepest moral commitments. What more could be required?

The trouble with this relativist view is that it is possible for a thinker's deepest moral commitments to include a specific claim about a difficult moral case - for instance, that some course of action is morally better than an alternative - without any connection to supporting considerations. So it will be possible for a thinker to have a justified moral belief concerning some difficult moral case without any appreciation of any morally relevant considerations or how they bear on the case. This is incompatible with the epistemic principle defended above.

More sophisticated versions of moral relativism face similar problems. For instance, consider the view that a moral claim is true relative to society if it is entailed by (or otherwise comports with) the society's moral standards. Presumably on this view, a thinker will be justified in having a moral belief if the belief is obviously entailed by her society's moral standards. And, again, it will be possible for a thinker to have a justified moral belief concerning some difficult moral case without any appreciation of supporting considerations or how they bear on the case.

This is not a completely decisive objection. It would be possible to put forward a version of moral relativism - or some other antirealist view - that avoids this problem. To do so one could resist my claim that the antirealist views have the epistemological consequences that I tried to saddle them with. Alternatively, one could develop an antirealist view according to which there

\footnotetext{
${ }^{40}$ See Schechter (forthcoming b) for an account of the epistemology of deductive inference designed to avoid the analogous problem.
} 
are no "isolated" moral truths about difficult moral cases. For instance, one might claim that it is impossible for a thinker's deepest moral commitments (or a society's moral standards) to include an isolated claim about a difficult moral case. So the objection is best understood as placing a constraint on antirealist views of morality - they must either fit with an epistemological view according to which moral beliefs about difficult moral cases cannot be justified in isolation or they must somehow entail that there are no isolated moral truths. It is not obvious how to develop such an antirealist view in a principled way.

\section{Moral Metaphysics II}

There is another, more general, reason to think that the epistemic principle stated above provides support to realist views of morality. Recall that the phenomenon concerning difficult cases is not particular to morality. There are analogous phenomena concerning complex scientific theories and difficult mathematical theorems. But there is no analogous phenomenon for beliefs attributing predicates of personal taste, such as beliefs about what is funny or what is delicious. What explains this difference? The natural suggestion to make is that we should be antirealists of some stripe about predicates of personal taste - there are no objective external standards about humor or taste. On the other hand, we should be realists of some stripe about science and mathematics. Our beliefs about science and mathematics aim at the external truth. Derivatively, our beliefs about science and mathematics (at least those concerning non-basic facts and held in a canonical way) are only justified if they are appropriately tied to supporting considerations. The moral case falls on the same side of the divide as science and mathematics, and on a different side from attributions of predicates of personal taste. This suggests that we should be realists about morality, too. ${ }^{41}$

Since there are analogous phenomena in the cases of moral belief, scientific belief, and mathematical belief, there is theoretical pressure to provide a unified explanation of these phenomena. Given that we ought to endorse broadly realist views of scientific and mathematical belief, this provides us with some reason to endorse a broadly realist view of morality. It also provides us with some reason to try to develop an account of the epistemic justification of moral belief that parallels the correct theory of the epistemic justification of scientific and mathematical belief. This suggests that moral belief should not be treated as different in kind from scientific and mathematical belief, at least in these respects. ${ }^{42}$

\footnotetext{
${ }^{41}$ I'm tempted by the idea that we should be realists of some stripe about certain aesthetic judgments. For a development of this view - somewhat tongue in cheek - see Loeb (2003). Notice, though, that insofar as we treat aesthetic judgments of a certain kind as falling on the realist side of the divide, our intuition is that such a judgment concerning a difficult case (held in a canonical way) is justified only if the thinker has some appreciation of the relevant aesthetic considerations and how they bear on the case.

42 This paper was presented at the 2015 Chapel Hill Metaethics Workshop. I'm grateful to numerous participants at the workshop for their questions and comments. Thanks to Casey Johnson, Michael Lynch, and Ram Neta for helpful discussions. Thanks to two anonymous referees for their useful and detailed comments. This paper was written while I was a visiting fellow at the University of Connecticut Humanities Institute. I'd like to thank the University of Connecticut for its hospitality.
} 


\section{References}

Arpaly, Nomy. 2002. Unprincipled Virtue, Oxford: Oxford University Press.

Bennett, Jonathan. 1974. "The Conscience of Huckleberry Finn," Philosophy 49(188): 123-134.

BonJour, Laurence. 1997. In Defense of Pure Reason, Cambridge: Cambridge University Press.

Goldman, Alvin. 1979. "What is Justified Belief?," in George Pappas (ed.), Justification and Knowledge, Dordrecht: Reidel, pp. 1-23.

Grimm, Stephen. 2006. "Is Understanding a Species of Knowledge?," British Journal for the Philosophy of Science 57(3): 515-535.

Harman, Elizabeth. MS. "Ethics is Hard! What Follows?".

Harman, Gilbert. 1977. The Nature of Morality, New York: Oxford University Press.

Huemer, Michael. 2006. Ethical Intuitionism, New York: Palgrave Macmillan.

Hills, Alison. 2009. "Moral Testimony and Moral Understanding," Ethics 120(1): 94-127.

Hills, Alison. 2010. The Beloved Self, Oxford: Oxford University Press.

Hills, Alison. 2015. "Understanding Why," Noûs.

Hopkins, Robert. 2007. "What is Wrong with Moral Testimony?," Philosophy and

Phenomenological Research 74(3): 611-634.

Jones, Karen. 1999. "Second-Hand Moral Knowledge," Journal of Philosophy 96(2): 55-78.

Kant, Immanuel. 1797. "On a Supposed Right to Lie from Philanthropy".

Kelp, Christoph. 2015. "Understanding Phenomena," Synthese 192(12): 3799-3816.

Khalifa, Kareem. 2011. "Understanding, Knowledge, and Scientific Antirealism," Grazer Philosophische Studien 83(1): 93-112.

Lasonen-Aarnio, Maria. 2011. "Unreasonable Knowledge," Philosophical Perspectives 24(1): 121.

Loeb, Don. 2003. "Gastronomic Realism - A Cautionary Tale," Journal of Theoretical and Philosophical Psychology 23(1): 30-49.

McGrath, Sarah. 2011. "Skepticism about Moral Expertise as a Puzzle for Moral Realism," Journal of Philosophy 108(3): 111-137.

Nickel, Philip. 2001. "Moral Testimony and its Authority," Ethical Theory and Moral Practice 4(3): 253-266.

Pryor, James. 2000. "The Skeptic and the Dogmatist," Noûs 34(4): 517-549.

Schechter, Joshua. Forthcoming a. "No Need for Excuses: Against Knowledge-First Epistemology and the Knowledge Norm of Assertion" in J. Adam Carter, Emma Gordon, and Benjamin Jarvis (eds.) Knowledge First, Oxford: Oxford University Press.

Schechter, Joshua. Forthcoming b. "Small Steps and Great Leaps in Thought: The Epistemology of Basic Deductive Rules," in Brendan Balcerak Jackson and Magdelana Balcerak Jackson (eds.), Reasoning, Oxford: Oxford University Press.

Singer, Peter. 1972. "Famine, Affluence, and Morality," Philosophy and Public Affairs 1(3): 229-243.

Sliwa, Paulina. 2012. "In Defense of Moral Testimony," Philosophical Studies 158(2): 175-195.

Sliwa, Paulina. 2014. "Understanding and Knowing," Proceedings of the Aristotelian Society 115(1): 57-74. 